\title{
The effect of reference position versus right lateral position on the intra-abdominal pressure in mechanically ventilated patients
}

\author{
Ghada Shalaby Khalaf Mahran*1, Sayed K. Abd-Elshafy' ${ }^{2}$, Manal Mohammed Abd El Neem ${ }^{1}$, Jehan A. Sayed ${ }^{2}$ \\ ${ }^{1}$ Department of Critical Care and Emergency Nursing, Faculty of Nursing, Assiut University, Assiut, Egypt \\ ${ }^{2}$ Department of Anesthesia and Intensive Care, Faculty of Medicine, Assiut University, Assiut, Egypt
}

Received: October 23, 2017

Accepted: December 28, 2017

Online Published: January 19, 2018

DOI: $10.5430 /$ jnep.v8n6p93

URL: https://doi.org/10.5430/jnep.v8n6p93

\begin{abstract}
Background and objective: Intra-abdominal hypertension (IAH) is a frequent plentiful problem in patients admitted to critical care units. It ranges from a surge incidence of morbidity and mortality to a particular need for nursing health care, so recognition of the occurrence of IAH is a very critical issue for critical care nurses and physician. This study aimed to recognize the effects of various body position with the various head of bed elevation on the intra-abdominal pressure (IAP) in patients with mechanical ventilation.

Methods: Design: A non-randomized, prospective observational study was used. Setting: Trauma and general intensive care units at Assuit University Hospitals. Method: In a prospective observational study, during the third day of mechanical ventilation, 60 patients were screened for IAP via a urinary catheter, in two various body positions in three separate degrees of the head of the bed (HOB) elevation $\left(0^{\circ}, 15^{\circ}\right.$, and $\left.30^{\circ}\right)$. The position was changed at least 4 hours apart over a 24 -h period.

Results: In lateral recumbence, IAP measurements were significantly elevated compared to supine position, they were 19.70 $\pm 3.09 \mathrm{mmHg}$ versus $16.00 \pm 3.14(p<.001), 22.80 \pm 3.56 \mathrm{mmHg}$ versus $19.03 \pm 2.95(p<.001)$, and $26.08 \pm 3.59 \mathrm{mmHg}$ versus $21.46 \pm 2.90$ versus $(p<.001)$ at $0^{\circ}, 15^{\circ}$, and $30^{\circ}$ respectively. The mean of IAP difference was $3.7 \pm 3.0 \mathrm{mmHg}$ at $0^{\circ}$, $3.8 \pm 1.00 \mathrm{mmHg}$ at $15^{\circ}$, and $5.5 \pm 1.01 \mathrm{mmHg}$ at $30^{\circ}(p<.005)$.

Conclusions: IAP reading is significantly elevated by changing from supine to lateral position especially with HOB elevation and significantly correlated with mortality rate in patients with mechanical ventilation
\end{abstract}

Key Words: Head of the bed, Intra-abdominal pressure, Right lateral, Reference supine position, Critical care nurse, Mechanical ventilation

\section{INTRODUCTION}

The pressure in the abdominal cavity is called intraabdominal pressure (IAP) and it is normally ranged from 0-5 mmHg in healthy person ${ }^{[1]}$ and 5-7 $\mathrm{mmHg}$ in the general patient population. ${ }^{[2]}$ Body weight, posture, abdominal muscles tension, and diaphragm movements all these factors are considerably affect IAP ${ }^{[3,4]}$.
Critical care nurses need to understand the factors that prompt patients to develop intra-abdominal hypertension (IAH) and abdominal compartment syndrome (ACS). Predicting and managing IAH and ACS are important to improve health outcomes. ${ }^{[2]}$ Various factors such as recent operation in the abdomen, sepsis, system failure and need for connection to mechanical ventilation with the use of positive

\footnotetext{
* Correspondence: Ghada Shalaby Khalaf Mahran; Email: ghada.mahran@ @ursing.aun.edu.eg; Address: Department of Critical Care and Emergency Nursing, Faculty of Nursing, Assiut University, Assiut, Egypt.
} 
end-expiratory pressure (PEEP) or auto-PEEP are associated with elevations in IAP. ${ }^{[5]}$

Intra-abdominal hypertension has a prevalence of at least $50 \%$ in the critically ill population and has been identified as an independent risk factor of death. However, many members of the critical care team do not evaluate the high blood pressure in the abdomen and do not realize the consequences of intra-abdominal hypertension without treatment. These consequences can be an abdominal compartment syndrome, multi-system organ failure, and it may lead to mortality rate of $40 \%-100 \% .^{[1,6]}$

\subsection{Background}

The pathology of IAH is a frequent occurrence in critical care units. It is essential for nurses to regularly monitor IAP and organ perfusion to predict adverse consequences and be proactive in the management of patients at risk. ${ }^{[7]}$ IAP measurement is effective, and efficient way for determining the existence of IAH. It can direct the management. ${ }^{[8]}$ The early detection of IAH is critical for preventing ACS and need intense monitoring of IAP in risky patients. The bedside nurses are usually measured IAP, and in a different occasion, critical care nurses $(\mathrm{CCN})$ initiate IAP monitoring serially. ${ }^{[9]}$

Patients who managed in intensive care units (ICU) are often immobile and ventilated for extended periods of time. Further, prolonged immobility often contributes to complications with muscle groups and multiple body organs, including the skin, the cardiovascular system and the respiratory system. ${ }^{[10]}$ The standard nursing practice routine in the intensive care unit often dictates that patients are re-positioned every two hours. There are numbers of positioning practices for critically ill patients. These include the supine position; the semi-Fowler position, which includes head of bed elevation by 30 degrees or more and elevation of heels to 30 degrees; as well as lateral positioning with $30^{\circ}$ rotation or less. These positions generate the lower interface pressure. ${ }^{[11]}$

However, most ICU patients are cared for with elevated head of bed (HOB) to 30 or 45 degrees to decrease ventilatorassociated pneumonia (VAP) prevalence (as an evidence). Moreover, this position decreases the rate of pressure ulcers, along with pressure reduction devices, and decubitus. ${ }^{[3,12]}$ There is little evidence that describes how the side position affects IAP. Therefore, the primary outcome of this trial was to assess the impact of right lateral position on the IAP measurements compared to reference supine position both with $15^{\circ}, 30^{\circ} \mathrm{HOB}$ elevations in patients with mechanical ventilation. The second aim was to correlate the IAP changes caused by position with the duration of MV, ICU stay and mortality rate in critically ill.

\subsection{Objectives of the trial}

Evaluate the impact of right lateral position on the IAP measurements compared to standard supine position both with $15^{\circ}, 30^{\circ} \mathrm{HOB}$ elevations in the patients connected to mechanically ventilation.

\subsection{Hypothesis}

(1) A considerable difference in intra-abdominal pressure with various body positions.

(2) A dramatic change in intra-abdominal pressure with different head of bed elevation.

\section{MATERIALS AND METHOdS}

\subsection{Design}

A non-randomized, prospective observational study.

\subsection{Setting}

We conducted this non-randomized, prospective observational study of the general and trauma ICUs at Assiut University Hospitals in the period between August 2016 and February 2017. This study took place included in an 11-bed intensive care unit.

\subsection{Subjects}

A total of 85 patients agreed to participate in the trail. Of these, 15 patients were withdrawn from the study due to disease aggravation threatening the patient's life (pulmonary embolism and heart failure); and 10 died before the third day of ICU admission; Thus, data analyses was carried out in 60 cases (see Figure 1).

The inclusion criteria were: (1) Age > 18 years old; (2) Mechanically ventilated patient; (3) Have indwelling urine catheter in place; (4) Length of ICU stays $\geq 48$ hours.

The exclusion criteria were: (1) Cardiac failure; (2) Pulmonary edema; (3) Underwent early surgical treatment primarily esophageal, gastric or bladder surgery; (4) Pregnant; (5) Morbid obesity; (6) Unlikely to survive for 24 hours; (7) Unable to lay flat for any reason.

\subsection{Intervention}

Content validity was done by 6 expertise: 3 expertise from critical care nursing staff and 3 from critical care medicine staff who reviewed the tools and the teaching booklet for clarity, relevance, comprehensiveness, understanding, applying and easiness for administration. The content is valid and reliable. Reliability was assessed by correlation coefficient with $>0.8$ considered strong. A Pilot study was conducted on $10 \%$ of patients for testing applicability, clarity and feasibility of study tools. 


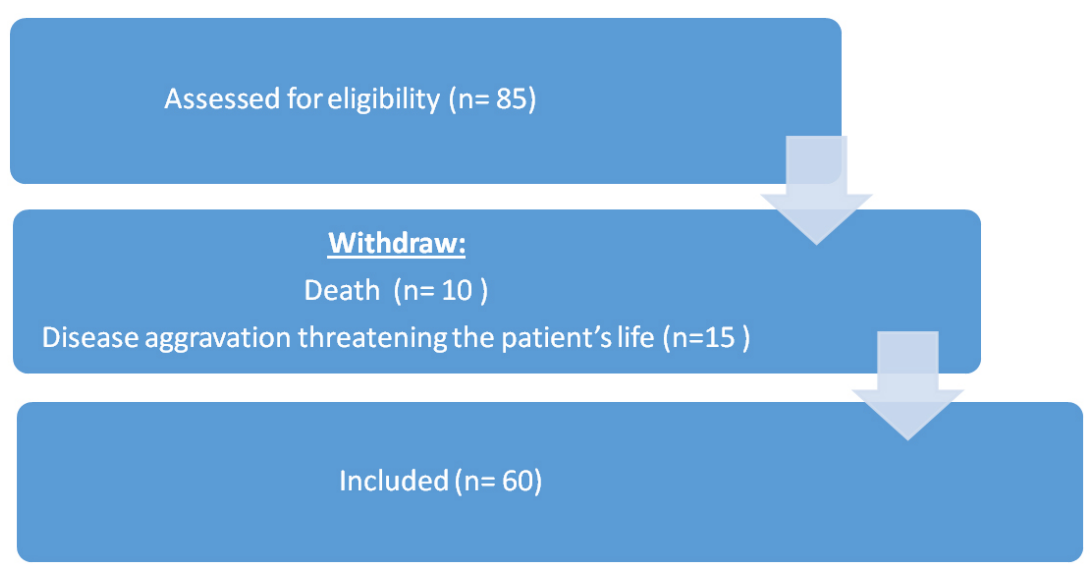

Figure 1. Pathway of the participants

The local ethics committee principles of faculty of nursing were followed by this trial (the Ethics Approval Number is 351). Written informed consent was obtained from patients' relatives or guidance that they willing to participate in the study after explaining the nature and the purpose of the study. They were told that they could withdraw their consent to participate at any time without having to face any negative consequences.

Measurements of IAP were performed in 60 adult patients, mechanically ventilated with Evita 4 (Drager Medical, Lübeck Germany) ventilators in a pressure control mode to keep patients' blood gasses within normal range.

To confirm the absence of abdominal muscle contractions, patients were sedated to a Richmond Agitation and Sedation Scale of 5 (RASS). IAP was measured during the third day of MV, via an indwelling urinary catheter in supine position with $25 \mathrm{ml}$ of normal saline of bladder volumes. The end of the catheter was connected to clear, open-ended plastic tubing, and the level of the water column above the midaxillary line reflects IAP. ${ }^{[13]}$

IAP is measured for the patients in various body positions; the supine (HOB-0, HOB-15, and HOB-30) followed by right lateral (HOB-0, HOB-15, and HOB-30), at least 4 hours apart over a 24 -h period. Intra-abdominal hypertension is graded into four categories; Grade I: IAP 12-15 mmHg, Grade II: IAP 16-20 mmHg, Grade III: IAP 21-25 mmHg, and Grade IV: IAP $>25 \mathrm{mmHg}$. Abdominal compartment syndrome is considered to be a sustained IAP $>20 \mathrm{mmHg}$, regardless of abdominal perfusion pressure, with a new organ dysfunction or failure. ${ }^{[2]}$

\subsection{Evaluation}

The meaning of IAP value was calculated as the level achieved among the measurements. The socio-demographic patient's profile and patient's clinical data, medical diagnosis,

Published by Sciedu Press duration of MV, a length of ICU stay, and lengths of hospital stay were assessed.

\subsection{Statistical interpretation}

All statistical interpretation were performed using IBM SPSS Statistics version 20 (SPSS Inc., Chicago, IL, USA). Descriptive statistics for mean $\pm \mathrm{SD}$ and median (range) were used to describe the sample. A coefficient of determination $\left(r^{2}\right)$ was used to determine the correlation between two variables. $p<.05$ was considered statistically significant.

\section{RESULT}

During the data collection period, 60 patients were included in the trial. $12(20 \%)$ patients had a primary diagnosis of Chronic Obstructive Pulmonary Disease (COPD). 24 (40\%) were Motor Car Accident (MCA) with brain edema and cerebral hemorrhage. 11 patients $(18.3 \%)$ had heat stroke. 7 patients $(11.7 \%)$ presented after firearm injury. 6 patients $(10 \%)$ were organophosphorus poisoning. The mean age was $54.80 \pm 12.10$ years. $80 \%$ of the patients were male (see Table 1).

The mean IAP at various $\mathrm{HOB}$ elevations $\left(\mathrm{HOB} 0^{\circ}\right.$, $\mathrm{HOB}$ $15^{\circ}$, and $\left.\mathrm{HOB} 30^{\circ}\right)$ in the reference were $(16.00 \pm 3.14)$ at $\mathrm{HOB} 0^{\circ}$ versus $(19.03 \pm 2.95)$ at $\mathrm{HOB} 15^{\circ}$ versus $(21.46 \pm$ $2.90)$ at $\mathrm{HOB} 30^{\circ}$ with $(p<.05)$. The mean IAP at various heads of the body (HOB) elevations (HOB $0^{\circ}, \mathrm{HOB} 15^{\circ}$, and HOB $\left.30^{\circ}\right)$ in the right lateral position was $(19.70 \pm 3.09)$ at HOB $0^{\circ}$ versus $(22.80 \pm 3.56)$ at $\mathrm{HOB} 15^{\circ}$ versus $(26.08 \pm$ $3.59)$ at $\mathrm{HOB} 30^{\circ}$ with $(p$ value $<.05)$ (see Table 2$)$.

The mean IAP at various $\mathrm{HOB}$ elevations $\left(\mathrm{HOB} 0^{\circ}\right.$, $\mathrm{HOB}$ $15^{\circ}$, and $\mathrm{HOB} 30^{\circ}$ ) in the reference and right lateral positions were $16.00 \pm 3.14$ versus $19.70 \pm 3.09 \mathrm{mmHg}$ with $p<.001$, $19.03 \pm 2.95$ versus $22.80 \pm 3.56 \mathrm{mmHg}$ with $p<.001$, and $21.46 \pm 2.90$ versus $26.08 \pm 3.59 \mathrm{mmHg}$ with $p<.001$. IAP difference was $3.7 \pm 3.0 \mathrm{mmHg}$ at $0^{\circ}, 3.8 \pm 1.00 \mathrm{mmHg}$ at $15^{\circ}$, and $5.5 \pm 1.01 \mathrm{mmHg}$ at $30^{\circ}$ (see Table 3 ). 
Table 1. Frequency distribution of patients regarding socio-demographic characteristics and clinical data

\begin{tabular}{ll}
\hline Items & \\
\hline Age & $54.80 \pm 12.10$ \\
Sex & $12(20 \%)$ \\
Female & $48(80 \%)$ \\
Male & \\
Diagnosis & $12(20 \%)$ \\
Chronic Obstructive Pulmonary Disease (COPD) & $24(40 \%)$ \\
Motor Car Accident (MCA) with brain edema, cerebral hemorrhage & $11(18.3 \%)$ \\
Heat stroke & $7(11.7 \%)$ \\
Fire Arm Injury (FAI) & $6(10 \%)$ \\
Organophosphorus poisoning & $15.21 \pm 9.31$ \\
Duration of mechanical ventilation (Hours) & $19.85 \pm 8.44$ \\
Length of Intensive Care Unit (Days)
\end{tabular}

Note. Data presented as mean $\pm \mathrm{SD}$, number (\%), or median (range)

Table 2. The mean \& SD of Intra-Abdominal Pressure (IAP) with different of head of bed elevation

\begin{tabular}{lllllc}
\hline Items & $\begin{array}{l}\text { Head of bed } \\
\text { elevation }\end{array}$ & Mean \pm SD & p value & \multicolumn{2}{c}{ 95\% Confidence Interval of the Difference } \\
\cline { 5 - 6 } & $0^{\circ}$ & $16.00 \pm 3.14$ & lower & Upper \\
\hline Intra-abdominal pressure & $15^{\circ}$ & $19.03 \pm 2.95$ & .000 & -4.135 & -1.931 \\
Supine position & $0^{\circ}$ & $16.00 \pm 3.14$ & & & -4.3724 \\
& $30^{\circ}$ & $21.46 \pm 2.90$ & .000 & -6.5609 & -1.891 \\
Intra-abdominal pressure & $0^{\circ}$ & $19.70 \pm 3.09$ & & \\
In right lateral position & $0^{\circ}$ & $22.80 \pm 3.56$ & .000 & -4.308 & -5.168 \\
& $30^{\circ}$ & $19.70 \pm 3.09$ & & & -7.597 \\
\hline
\end{tabular}

Table 3. The mean \& SD of Intra-Abdominal Pressure (IAP) with different body position

\begin{tabular}{|c|c|c|c|c|c|}
\hline \multirow{2}{*}{ Positions } & \multirow{2}{*}{ Head of bed elevation } & \multirow{2}{*}{ Mean \pm SD } & \multirow{2}{*}{$p$ value } & \multicolumn{2}{|c|}{ 95\% Confidence Interval of the Difference } \\
\hline & & & & lower & Upper \\
\hline $\begin{array}{l}\text { Reference position } \\
\text { Right lateral position }\end{array}$ & $0^{\circ}$ & $\begin{array}{l}16.00 \pm 3.14 \\
19.70 \pm 3.09\end{array}$ & $<.001$ & -4.828 & -2.572 \\
\hline $\begin{array}{l}\text { Reference position } \\
\text { Right lateral position }\end{array}$ & $15^{\circ}$ & $\begin{array}{l}19.03 \pm 2.95 \\
22.80 \pm 3.56\end{array}$ & $<.001$ & -4.950 & -2.582 \\
\hline $\begin{array}{l}\text { Reference position } \\
\text { Right lateral position }\end{array}$ & $30^{\circ}$ & $\begin{array}{l}21.46 \pm 2.90 \\
26.08 \pm 3.59\end{array}$ & $<.001$ & -5.244 & -3.989 \\
\hline
\end{tabular}

IAP grading between all positions showed a statistically significant increase by head of bed elevation. In supine (reference), position 6 patients $(10 \%)$ were in grade I (12-15 $\mathrm{mmHg}$ ) at HOB $0^{\circ}$. This number increased to be $31(51.66 \%)$ patients in grading II, when the HOB elevated to $15^{\circ}$ and become $35(53.03 \%)$ in grade III when HOB at $30^{\circ} .38$ $(63.33 \%)$ patients were in grade $\mathrm{II}$ at $0^{\circ}$ but this number increased to be $19(31.66 \%)$ in grade III then $2(3.33 \%)$ in grade IV when $\mathrm{HOB}$ elevated to $15^{\circ}$ then $30^{\circ}$. In right lateral, 8 patients $(13.33 \%)$ were in grade $\mathrm{I}(12-15 \mathrm{mmHg})$ at HOB $0^{\circ}$. This number increased to be 13 patients (21.66\%) in grading II, when the $\mathrm{HOB}$ elevated to $15^{\circ}$ and become $16(26.66 \%)$ in grade III when HOB at $30^{\circ} .28(46.66 \%)$ patients were in grade II at $0^{\circ}$ but this number increased to be $34(56.66 \%)$ in grade III then $39(65 \%)$ in grade IV when HOB elevated to $15^{\circ}$ then $30^{\circ}$ (see Table 4). 
Table 4. Frequency distribution of Intra-Abdominal Pressure (IAP) Grading, number (\%)

\begin{tabular}{|c|c|c|c|c|c|c|c|c|c|}
\hline \multirow{2}{*}{$\begin{array}{l}\text { Grading of } \\
\text { intra-abdominal } \\
\text { pressure (IAP) }\end{array}$} & \multicolumn{3}{|l|}{ Supine } & \multicolumn{3}{|l|}{ Right lateral } & \multirow{2}{*}{$p 1$} & \multirow{2}{*}{$p 2$} & \multirow{2}{*}{ p3 } \\
\hline & IAP at $0^{\circ}$ & IAP at $15^{\circ}$ & IAP at $30^{\circ}$ & IAP at $0^{\circ}$ & IAP at $15^{\circ}$ & IAP at $30^{\circ}$ & & & \\
\hline$<12$ & 13 (21.66\%) & $0(0 \%)$ & $0(0 \%)$ & $0(0 \%)$ & $0(0 \%)$ & $0(0 \%)$ & & & \\
\hline $12-15$ & $6(10 \%)$ & 10 (16.66\%) & $2(3.33 \%)$ & 8 (13.33\%) & $1(1.66 \%)$ & $0(0 \%)$ & & & \\
\hline $16-20$ & 38 (63.33\%) & 31 (51.66\%) & 21 (35\%) & 28 (46.66\%) & 13 (21.66\%) & 5 (8.33\%) & .001 & .001 & .001 \\
\hline $21-25$ & $3(5 \%)$ & 19 (31.66\%) & 35 (53.03\%) & 22 (36.66\%) & 34 (56.66\%) & 16 (26.66\%) & & & \\
\hline$>25$ & $0(0 \%)$ & $0(0 \%)$ & $2(3.33 \%)$ & 2 (3.33\%) & $12(20 \%)$ & 39 (65\%) & & & \\
\hline
\end{tabular}

$* p 1$ value $<.05$ between supine position at $0^{\circ}$ and right lateral position at $0^{\circ}$

${ }^{*} p 2$ value $<.05$ between supine (reference) position at $15^{\circ}$ and right lateral position at $15^{\circ}$

${ }^{*} p 3$ value $<.05$ between reference position at $30^{\circ}$ and right lateral position at $30^{\circ}$

\section{Discussion}

Critical care nurses play vital role in constant observation and recognition of subtle and dynamic changes in the status of critically ill patients in the ICU. Therefore, a CCN must have a good understanding of the concept of IAH and ACS and their clinical significance in order to promptly recognize and appropriately manage these conditions as members of the ICU team. ${ }^{[9]}$

This study showed that the mean and standard deviation of IAP was elevated when the position changed from the reference supine to the right lateral. These findings were similar to that of De Keulenaer et al. ${ }^{[3]}$ They included ten patients to test the lateral decubitus position versus the standard supine position impact on IAP at a various time intervals (morning, afternoon and evening). The mean of IAP at these various time intervals in the supine versus lateral positions were 6.6 \pm 3.2 versus $10.9 \pm 2.0 \mathrm{mmHg}$, with $p=.001,5.4 \pm 2.2$ versus $11.0 \pm 4.0, p=.0005$, and $7.8 \pm 3.0$ versus $11.6 \pm$ 3.8. While, the findings of this study were against the results of Lopes et al., ${ }^{[14]}$ who found no statistically considerable differences between IAP $(p<.05)$ in lateral, ventral and dorsal positions in dogs.

With regard to the effect of the head of the bed height (HOB) on IAP, this latter trial confirmed a considerable increase in the mean and standard deviation of IAP with head elevation. These results guide the nursing practice when positioning the patients at risk for intra-abdominal hypertension. The nurses should minimize head of bed elevation in those patients not more than $30^{\circ}$. These results were consistent with Rooban et al. ${ }^{[12]}$ who enrolled 20 patients in his study to compare IAP in the standard reference position versus HOB the $30^{\circ} \mathrm{HOB}$ position by intra-bladder pressure (IBP) and intra-gastric pressure (IGP). The mean IGP was $11.8 \pm 4.7$ mmHg compared to an IBP of $12.3 \pm 4.5 \mathrm{mmHg}$, in the reference position. The mean IBP was $15.8 \pm 4.9 \mathrm{mmHg}$, in $\mathrm{HOB} 30^{\circ}$ position vs. an IGP of $13.1 \pm 6.1 \mathrm{mmHg}$. The mean difference in the reference position for IGP and IBP was $-1.3 \pm 4.6 \mathrm{mmHg}(p=.037)$, while, the mean difference in the HOB $30^{\circ}$ for IGP and IBP was $-3.5 \pm 3.0 \mathrm{mmHg}(p$ $<0.001)$. A similar but larger prospective multi-center trial was conducted by Cheatham et al. ${ }^{[8]}$ which included 132 patients examining the effect of various positions of the body on IAP. They confirmed a mean IAP difference of $1.5 \mathrm{mmHg}$ at $15^{\circ}$ and $3.6 \mathrm{mmHg}$ at $30^{\circ}$. Moreover, IAP was monitored by (Vasquez, Berg-Copas, \& Wetta-Hall, 2007) ${ }^{[15]}$ they included 45 patients with trauma, comparing the reference position vs. various elevations of HOB. They founded a dramatic rise in the average IAP in the reference position vs. those at $\mathrm{HOB} 45^{\circ}$ (10.2 versus $16.7 \mathrm{mmHg}$ ).

These findings were in contrast with Cresswell et al. ${ }^{[16]}$ who reported that, the mean upper intra-abdominal pressure (UIAP) when lying supine was $11.7 \mathrm{mmHg}$, vs. 9.60 $\mathrm{mmHg}$ with elevated head of bed to $30^{\circ}(p<.001)$. Also, the mean lower intra-abdominal pressure (LIAP) was 9.20 $\mathrm{mmHg}$ when supine and increased to $9.60 \mathrm{mmHg}$ when the head of the bed elevated to $30^{\circ}(p<.001)$ following liver transplantation. However, Cresswell et al. ${ }^{[16]}$ included 51 ICU patients and found that in the $30^{\circ}$ supine position, the abdominal wall tension (AWT) was lower than that of the supine position $0^{\circ}$. They explained that when the head of the bed was elevated, the wall of the abdominal muscles relaxed and the AWT decreased.

Due to the increased incidence of IAH and ACS, it is essential for critical care nurses to regularly monitor IAP and APP. Critical care nurses have the ability to recognize IAH and ACS, implement and evaluate management interventions. Nursing care should be centered on evidence based practice guidelines. ${ }^{[17]}$

Based on the new classifications of IAH grades, there was an elevation in IAP grading in our readings, when elevating the head of the bed. These results were in line with De Keulenaer et al. ${ }^{[3]}$ who found a significant change in grading 
with increased elevation of the bed where IAP at 45 degrees would overburden by two full degrees. Thus, patients at a high risk for development of IAH and ACS could experience a grade 3 or 4 IAH or even ACS in high position.

\section{Conclusion}

Changing body position during care of patients with mechanical ventilation from supine to right lateral was increasing the readings of IAP especially if associated with $\mathrm{HOB}$ elevations.

Based on the finding of the current study, the following recommendations are suggested:

Recommendations for nursing education:

- The latest guidelines of ACS should be available in written format in critical care units and emergency units.

- Included in-hospital ACS teaching program in the schools and undergraduates' curriculum.
- Pre-employment orientation, in-service education and training programs regarding ACS should be for all.

- Learning facilities such as update resources available to promote self-learning regarding ACS.

- The findings of the study can add value to nursing education if included in the critical care nursing curriculum offered at nursing colleges and universities.

Recommendations for nursing practice:

- Consider supine position $<20^{\circ}$-Avoid prone position.

- Restriction of fluids/permissive hypotension in trauma.

- Optimize ventilation, alveolar recruitment.

- Regular monitoring of IAP of high risk patients as ventilated patients.

\section{CONFlicts OF InTEREST Disclosure}

The authors declare that there is no conflict of interest statement.

\section{REFERENCES}

[1] Lee RK. Intra-abdominal hypertension and abdominal compartment syndrome a comprehensive overview. Critical Care Nurse. 2012 32(1): 19-31. PMid:22298715 https://doi .org/10.4037/ccn2 012662

[2] Hunt L, Frost SA, Newton PJ, et al. A survey of critical care nurses' knowledge of intra-abdominal hypertension and abdominal compartment syndrome. Australian Critical Care. 2017; 30(1): 21-27. PMid:27036928 https://doi.org/10.1016/j.aucc.2016.02 .001

[3] De Keulenaer B, De Waele J, Powell B, et al. What is normal intraabdominal pressure and how is it affected by positioning, body mass and positive end-expiratory pressure? Intensive Care Medicine. 2009; 35(6): 969-976. PMid:19242675 https://doi .org/10.1007/s0 0134-009-1445-0

[4] Kyoung KH, Hong SK. The duration of intra-abdominal hypertension strongly predicts outcomes for the critically ill surgical patients: a prospective observational study. World Journal of Emergency Surgery. 2015; 10(1): 22. PMid:26056530 https://doi.org/10.1186/s1 3017-015-0016-7

[5] Morejón CDS, Barbeito TOT. Effect of mechanical ventilation on intra-abdominal pressure in critically ill patients without other risk factors for abdominal hypertension: An observational multicenter epidemiological study. Annals of intensive care. 2012; 2(1): S22. PMid:23281625 https://doi.org/10.1186/2110-5 820-2-S1-S22

[6] Harris H, Smith CJ. Understanding abdominal compartment syndrome. Nursing Critical Care. 2013; 8(3): 45-47. https ://doi. or g/10.1097/01.CCN.0000429385.10473.7f

[7] Spencer P, Kinsman L, Fuzzard K. A critical care nurse's guide to intra abdominal hypertension and abdominal compartment syndrome. Australian Critical Care. 2008; 21(1): 18-28. PMid:18201894 https://doi.org/10.1016/j.aucc.2007.10.005

[8] Cheatham ML, De Waele JJ, De Laet I, et al. The impact of body position on intra-abdominal pressure measurement: a multicenter analysis. Critical Care Medicine. 2009; 37(7): 2187-2190. PMid:19487946 https://doi.org/10.1097/CCM.0b013e3181a021fa
[9] Newcombe J, Mathur M, Bahjri K, et al. Pediatric critical care nurses' experience with abdominal compartment syndrome. Annals of Intensive Care. 2012; 2(1): S6. PMid:22873422

[10] Vollman KM. Introduction to progressive mobility. Critical Care Nurse. 2010; 30(2): S3-S5. PMid:20360443 https://doi .org/10 $.4037 / \operatorname{ccn} 2010803$

[11] Johnson KL, Meyenburg T. Physiological rationale and current evidence for therapeutic positioning of critically ill patients. AACN Adv Crit Care. 2009; 20(3): 228-240. PMid:19638744

[12] Rooban N, Regli A, Davis WA, et al. Comparing intra-abdominal pressures in different body positions via a urinary catheter and nasogastric tube: a pilot study. Annals of Intensive Care. 2012; 2(1): S11. PMid:22873412 https://doi .org/10.1186/2110-5 820-2-S1-S11

[13] Shuster MH, Haines T, Sekula LK, et al. Reliability of intrabladder pressure measurement in intensive care. American Journal of Critical Care. 2010; 19(4): e29-e39. PMid:20595210 https://doi.org/ $10.4037 /$ ajcc2010204

[14] Lopes AM, Nunes A, Niza MM, et al. Intra-abdominal Pressure is Influenced by Body Position? American Journal of Clinical Medicine Research. 2016; 4(1): 11-18.

[15] Vasquez DG, Berg-Copas GM, Wetta-Hall R. Influence of semirecumbent position on intra-abdominal pressure as measured by bladder pressure. Journal of Surgical Research. 2007; 139(2): 280285. PMid:17161433 https://doi.org/10.1016/j.jss. 2006 .10 .023

[16] Cresswell AB, Jassem W, Srinivasan P, et al. The effect of body position on compartmental intra-abdominal pressure following liver transplantation. Annals of Intensive Care. 2012; 2(1): S12. PMid:22873413 https://doi.org/10.1186/2110-5820-2-S $1-\mathrm{S} 12$

[17] Hunt L, Frost SA, Hillman K, et al. Management of intra-abdominal hypertension and abdominal compartment syndrome: a review. Journal of Trauma Management \& Outcomes. 2014; 8(1): 2. PMid:24499574 https://doi .org/10.1186/1752-2897-8-2 